\title{
The effect of the difference time grinding on the structure and morphology of Aluminum Oxide $\left(\mathrm{Al}_{2} \mathrm{O}_{3}\right)$
}

\author{
Halo Dalshad Omar \\ Department of Physics, Faculty of Science and Health, Koya University \\ Daniel Mitterrand Boulevard, Koya KOY45 AB64, Kurdistan Region - Iraq \\ E-mail address: halo.dalshad@koyauniversity.org
} Keywords: X-Ray Diffraction $(\mathrm{XRD})$, Scanning Tunneling Microscope (STM), Mini Mill 2
Panalytical, Aluminum Oxide $\left(\mathrm{Al}_{2} \mathrm{O}_{3}\right)$

\begin{abstract}
The objective of the paper has been given on the observations based on the studies on aluminum oxide $\left(\mathrm{Al}_{2} \mathrm{O}_{3}\right)$ powder or alumina for different time grinding.

A discussion about simple and low cost preparation of $\mathrm{Al}_{2} \mathrm{O}_{3}$ powder by (Mini Mill 2 Panalytical) and preparation of the sample was rotating at $0,5,10$ and $15 \mathrm{~min}$ and in the case of grinding of samples at high speed $659 \mathrm{rpm}$. Structure and morphology of aluminum oxide $\left(\mathrm{Al}_{2} \mathrm{O}_{3}\right)$ powder its characterizations (XRD (Model: Panalytical Empyrean) and STM (Model: NTMDT Solver Nano.)) are studied in this research paper.
\end{abstract}

\section{INTRODUCTION}

Alumina $\left(\mathrm{Al}_{2} \mathrm{O}_{3}\right)$ shows excellent physical and chemical properties, including the highest strength among oxides, excellent abrasion resistance, heat resistance, a high dielectric strength at high voltage, and high resistance to chemical attack [9-11].

$\mathrm{X}$-ray diffraction is one of the most powerful tools for identifying unknown crystalline phases [14]. By comparing the positions and intensities of the diffraction peaks against a library of known crystalline materials, the test sample can be identified [18]. The powder metallurgy route for manufacturing composites materials offers some advantages compared with ingot metallurgy or diffusion welding, Alumina powder is a commonly used raw material in support preparation processes [2-4]. $\mathrm{Al}_{2} \mathrm{O}_{3}$ is the most stable type among various crystal phases because of its high lattice energy, high hardness, hard ground, and easy agglomeration [6-15].

The crystalline phase and average crystallite size of the powder were determined by X-ray diffraction (XRD) [1-3]. A scanning tunneling microscope (STM) was used to investigate the roughness and morphology. The STM analyses the surface of alumina, producing images of higher resolution.

\section{SAMPLE PREPARATION BY MINI MILL 2 PANALYTICAL}

Before grinding aluminum oxide powder by Minimill 2 was cleaned the bowl with acetone for a short time [5]. The hardness of the grinding bowl used and of the grinding balls must be higher than of the $\mathrm{Al}_{2} \mathrm{O}_{3}$ used. The grinding bowls and grinding balls of aluminum oxide are resistance to acids with the exception of hydrofluoric acid. In accordance with the application, the grinding time should be adapted of the bowl. $\mathrm{Al}_{2} \mathrm{O}_{3}$ powders have investigated different time $0,5,10$ and $15 \mathrm{~min}$ and in the case of grinding for all samples at high speed $659 \mathrm{rpm}$.

\section{X-RAY DIFFRACTION STUDY OF ALUMINUM OXIDE $\left(\mathrm{Al}_{2} \mathrm{O}_{3}\right)$}

X-ray diffraction is one of the most important characterization tools used in solid state chemistry and materials science [7-13]. XRD is an easy tool to determine the size and the shape of the unit cell for any compound. XRD used to determine peak position was carried out using a Panalytical. $\mathrm{Cu} X$-ray tube $(\lambda=0.15406 \mathrm{~nm})$ equipped with a $1 \times 1 \mathrm{~mm}^{2}$ point focus and a Nickel 
filter on the direct beam path to absorb the $\mathrm{Cu} \mathrm{K}$ radiation. The incident beam is collimated with a $1 \mathrm{~mm}$. Diameter collimator and focused on the sample mounted on a four-circle goniometer [10-16]. $\mathrm{X}$-ray diffraction patterns of grain as shown in the fig. 1 and different time $\mathrm{Al}_{2} \mathrm{O}_{3}$ powder. Figure 2 also shows that under the same applied different grinding time for the position $2 \theta$ between $34^{\circ}$ and $39^{\circ}$.

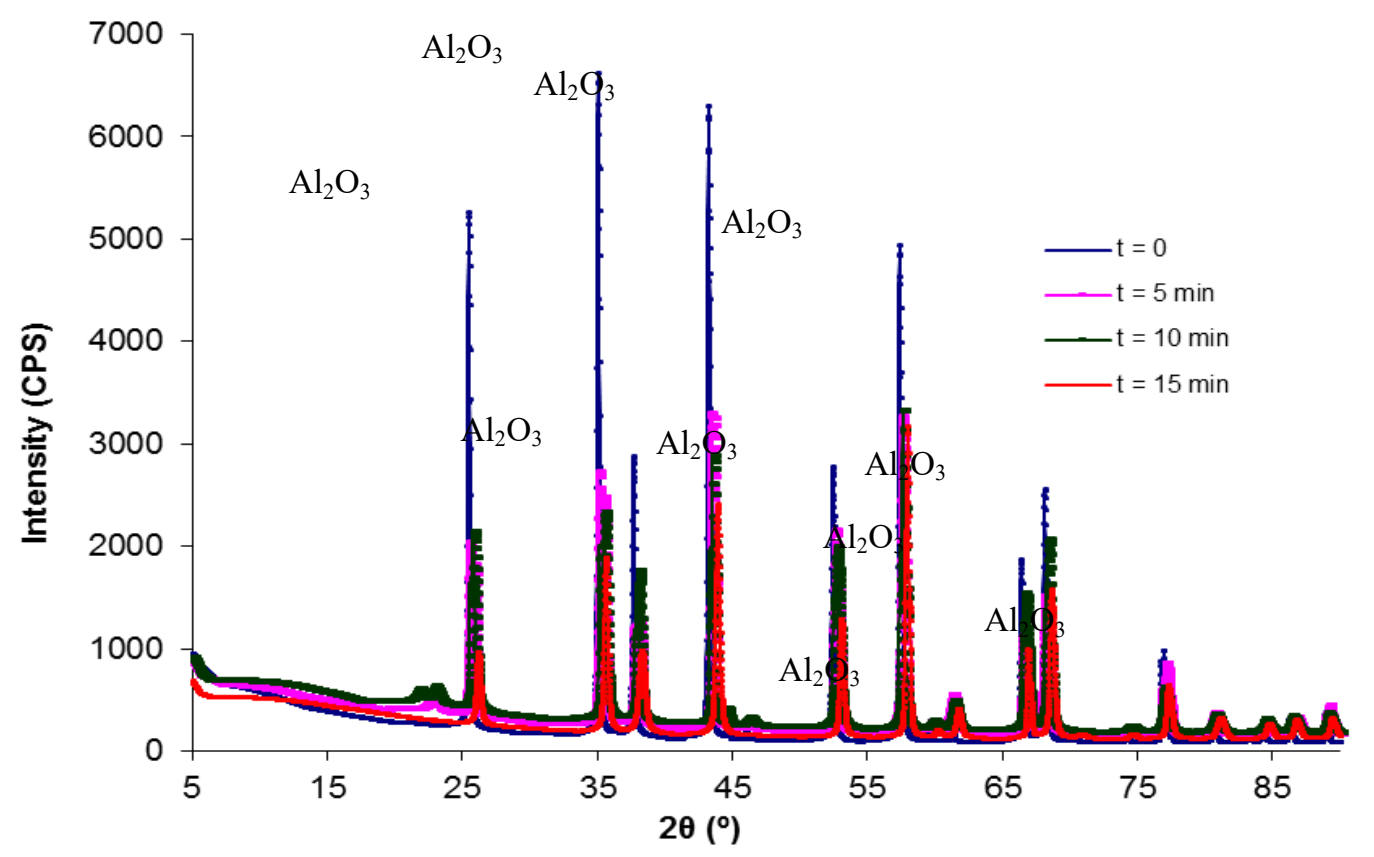

Fig.1. Variation of time grinding $\mathrm{x}$-ray diffraction patterns of $\mathrm{Al}_{2} \mathrm{O}_{3}$.

The XRD quantitative analysis for measuring crystallite size and determining alumina phase concentrations, a quantitative analysis of diffractogram patterns for each sample including crystallite sizes and concentration of alumina phases formed was applied and assisted using XRD software. The average crystallite size was calculated using the Debye-Scherrer formula [3-5]:

$D=\frac{0.9 \lambda}{\beta \cos \theta}$

Where ' $\lambda$ ' is wave length of X-Ray $(1.5406(\AA))$, ' $\beta$ ' is FWHM (full width at half maximum), ' $\theta$ ' is the diffraction angle and ' $\mathrm{D}$ ' is is the crystallite size.

XRD analysis of the prepared sample of alumina or aluminum oxide powder was done by a Panalytical (Under $45 \mathrm{kV} / 40 \mathrm{~mA}$ - X-Ray, $2 \theta / \theta$-Scanning mode). Data was taken for the $2 \theta$ range of 5 to 90 degrees with a step of 0.013 degree.

The XRD patterns of the aluminum oxide peaks at $2 \theta$ angles values approximately of $26.35,35.44$, $37.54,44.14,53.30,58.22,61.94,67.25,68.87$ and 77.52 deg corresponding to the (012), (104), (110), (113), (202), (024), (116), (018), (214) and (1010) planes of aluminum oxide were observed and compared with the standard powder diffraction [8-12].

For studied samples the preferential orientation value of (104) plane has the highest value compared to other planes. The obtained result indicates a strong orientation along the (104) plane. Based on the line width of the (104) diffraction peak, the crystalline grain size for the $\mathrm{Al}_{2} \mathrm{O}_{3}$ with differing times grinding as shown in Fig. 2, and the intensity for all peaks decreasing with increasing times grinding by (Mini Mill 2 Panalytical). 


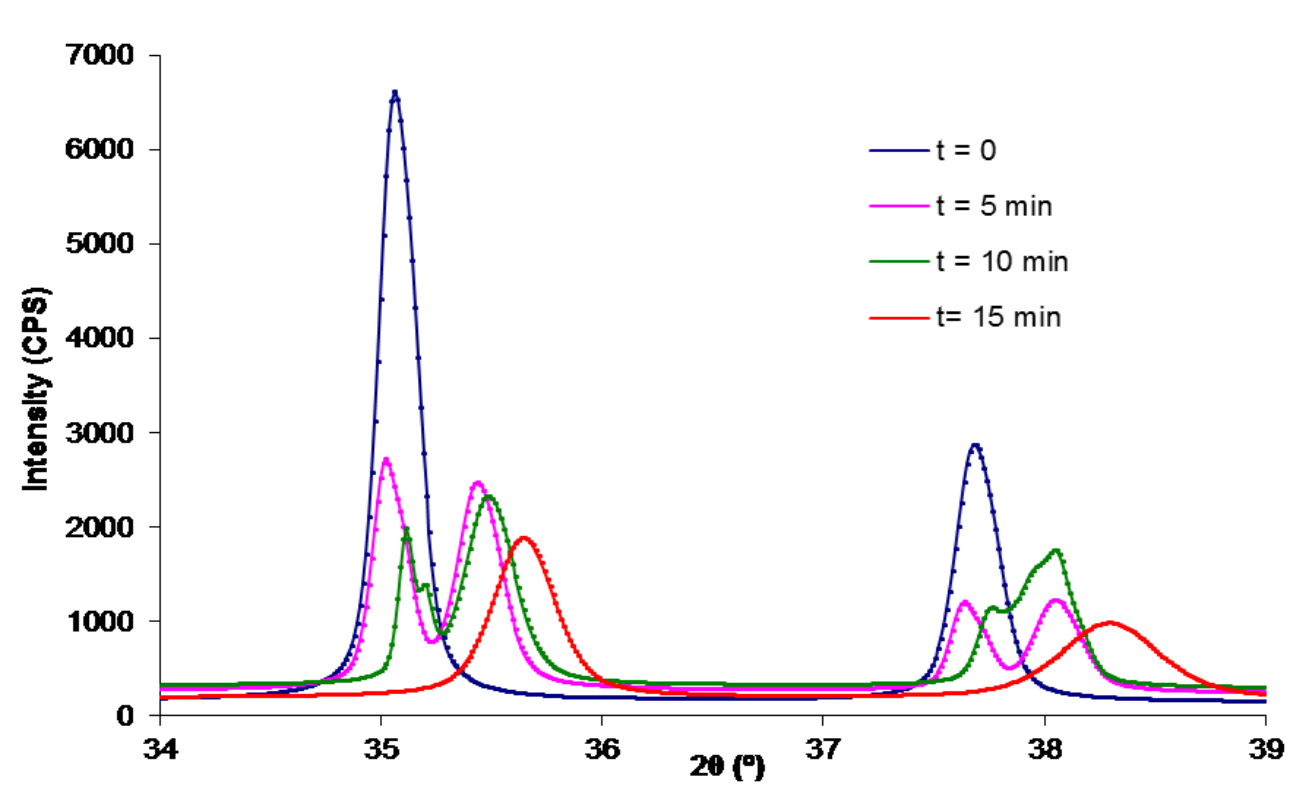

Fig.2. Difference time grinding aluminum oxide powder by XRD at $2 \theta=34^{\circ}-39^{\circ}$.

The crystallite size (D) increase with increasing times grinding by (Mini-Panalytical) and the maximumt value-D at $\mathrm{t}=15 \mathrm{~min}$. as shown in the table (1).

Table.1. The grain size increase with increasing times grinding.

\begin{tabular}{|c|c|c|c|c|}
\hline $2 \theta$ & $\mathrm{t}=0 \mathrm{~min} / \mathrm{D}(\AA)$ & $\mathrm{t}=5 \mathrm{~min} / \mathrm{D}(\AA)$ & $\mathrm{t}=10 \mathrm{~min} / \mathrm{D}(\AA)$ & $\mathrm{t}=15 \mathrm{~min} / \mathrm{D}(\AA)$ \\
\hline$\approx 35.44^{\circ}$ & 671.98 & 851.66 & 1180.34 & 1578.32 \\
\hline
\end{tabular}

\section{SCANNING TUNNELING MICROSCOPIC (STM)}

The STM provides real space atomic resolution images through tunneling current between a tip (Pt-Ir) and an aluminum oxide surface [5]. Characterized for their crystal structure and surface morphology [17]. The surface roughness was measured by using STM. Shows the surface morphology of different times $5 \mathrm{~min}, 10 \mathrm{~min}$ and $15 \mathrm{~min}$ as shown in Fig.3. From STM images it was found that the root mean square roughness with $500 \times 500$ points, and scanning rate of $0.8 \mathrm{~Hz}$, applied voltage $2.14 \mathrm{nV}$ and the current between surface iron metallic and tip was $5.0 \mathrm{nA}$.

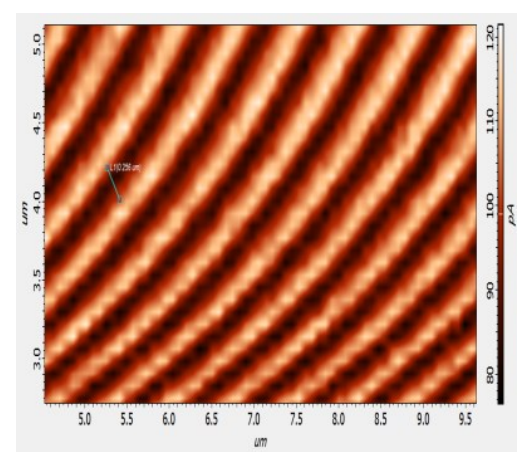

(a)

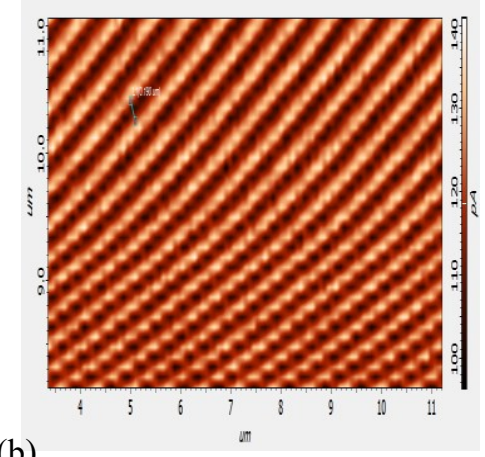

(b)

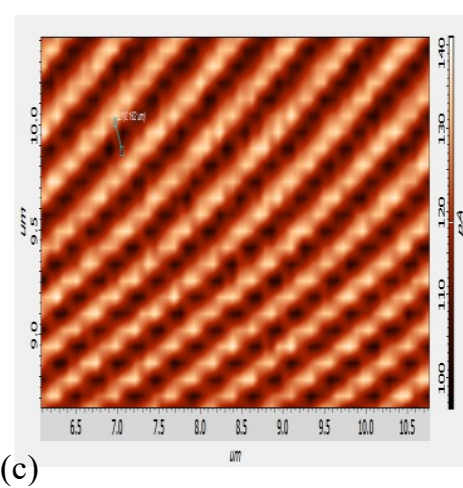

(c)

Fig.3. STM image of surface aluminum oxide of $2 D$ at (a) $t=5 \min (b) t=10 \min$ (c) $\mathrm{t}=15 \mathrm{~min}$.

\section{RESULT AND CONCLUSION}

The XRD study confirms / indicates that the resultant particles are $\left(\mathrm{Al}_{2} \mathrm{O}_{3}\right)$ by diffraction pattern presented in the Fig. 1 . To investigation of the different time grinding of the peaks $\mathrm{Al}_{2} \mathrm{O}_{3}$ by XRD, the increasing time of grinding samples affect to decrease the intensity of the peaks $\mathrm{Al}_{2} \mathrm{O}_{3}$. Show the double peak visible at the position $35^{\circ}$ and $36^{\circ}$ also the peak is shift of the origin position. The crystallite size (D) increase with increasing times grinding by (Mini-Panalytical) as shown in 
the table (1). Aslo the effect of the grinding time on the image topography STM, to surfaces of the products of $\mathrm{Al}_{2} \mathrm{O}_{3}$ were obviously smooth. The evaluated root mean square (RMS) surface roughness of the samples at $\mathrm{t}=5$ min was $\mathrm{RMS}=3.07 \mathrm{~nm}, \mathrm{t}=10 \min$ was $\mathrm{RMS}=2.45 \mathrm{~nm}$ and $\mathrm{t}=15$ min was RMS $=1.58 \mathrm{~nm}$, as seen in the Fig. 3 .

\section{References}

[1] B. D. Cullity and S. R. Stock, Elements of X-Ray Diffraction, Associate Professor of Metallurgy in University of Notre Dame, 1978.

[2] Charles Kittel, Introduction to Solid State Physics (Wiley; 8th Edition, 2004)(ISBN 047141526X).

[3] Halo Dalshad Omar, To Investigation the Structure and Morphology of Iron Metallic by Difference Techniques,Department of Physics, School of Science, University of Koya, J. Nano. Adv. Mat. 3, No. 2, 57-61, 2015.

[4] Alan Lawley, International Journal of Powder Metallurgy - Focus Issue: Precious Metals, Platinum Metals Rev., 2010, 54, (2), 122-124.

[5] Halo Dalshad Omar, Surface analysis and roughness parameters of Copper Metallic, International Letters of Chemistry, Physics and Astronomy Vol. 57 (2015) pp 66-71. doi:10.18052/www.scipress.com/ILCPA.57.66.

[6] Rifki Septawendar, Suhanda and Frank Edwin, Nanocrystalline $\alpha$-A12O3powder preparation with sucrose as a template through a chemical route, Journal of ceramic processing resarch Vol.12, No. 4, pp. 365-370 (2011).

[7] Hadi Fallah Moafi and Seyed Morteza Mostashari, Flame-resistant polymeric composite fibers based on nanocoating flame retardant: thermogravimetric study and production of $\alpha-\mathrm{Al}_{2} \mathrm{O}_{3}$ nanoparticles by flame combustion, J Polym Eng ; 34(9): 803-812, 2014.

[8] Yendrapati Taraka Prabhu, Kalagadda Venkateswara Rao, Vemula Sesha Sai Kumar, Bandla Siva Kumari, X-Ray Analysis by Williamson-Hall and Size-Strain Plot Methods of ZnO Nanoparticles with Fuel Variation, World Journal of Nano Science and Engineering, 4, 21-28, 2014.

[9] Chiang, Birnie III, and Kingery, "Physical Ceramics," Wiley, MIT, 1997.

[10] J.A. Rodriguez and M.F. Garcia, Synthesis, Properties, and Applications of Oxide Nanomaterials, Willey Interscience, New Jersey, (2007).

[11] Y. Sarikaya and M. Akinc, Ceram Int. 14 (1988) 239-244.

[12] Y. Lee, Y.M. Hahm and D.-H. Lee, J. Ind. Eng. Chem.,10 (2004) 826-833.

[13] Kemmlein S, Hahn O, Jann O. Atmos. Environ., 37, 5485-5493, 2003.

[14] Klaus O, Andreas W, Thomas B, Eckhard S. Polym. Degrad. Stab.96, 393-395, 2011.

[15] Hao J, Lewin M, Wilkie CA, Wang J. Polym. Degrad. Stab.91, 2482-2485, 2006.

[16] Mostashari SM, Moafi HF. J. Therm. Anal. Cal.93,589-594, 2008.

[17] T. Bastomi, B.S. Purwasasmita and R. Septawendar, inProceeding of Ceramic National Seminar VIII, "The Development of Ceramic Research Result through A Collaboration with Industries To Improve The Competitiveness and The Added Value of The Industrial Products", May 27, Savoy Homan, West Java, Indonesia, p.99-104, 2009.

[18] The Royal Society \& The Royal Academy of Engineering. Nanoscience and nanotechnologies: opportunities and uncertainties, London, (2004), Retrieved 2008-05-18 